\title{
A Whole-Process Innovative Education on Undergraduate Students Based on Scientific Investigations
}

\author{
Yanan Liu, Wanli He, Shiri Guo, Wenhui Zhou and Dengguang Yu* \\ School of Materials Science \& Engineering, University of Shanghai for Science \& Technology, 516 Jungong Road, \\ Shanghai 200093, China. \\ *Corresponding author. Email: ydg017@usst.edu.cn
}

\begin{abstract}
Backgrounds \& Objective: Three-comprehensive education is presently going on in all the China colleges and universities. Effectively carrying out this activity should be very useful for fostering the undergraduate students into the professional talents in future. Methods: Scientific investigations can be extracted out many useful teaching materials for giving three-comprehensive education, and they are extremely helpful for cultivating the students' innovative ability. Results: With electrospinning and electrospun medicated nanofibers as the research topics, which are taken place in the Lab of Electrohydridynamic Atomization \& Its Application in Creating Novel Materials (the School of Materials Science and Engineering in the University of Shanghai for Science and Technology). It is demonstrated that the undergraduate students are able to put forward brand-new idea and fruitful results during their three-comprehensive education processes. Conclusions: There are numerous positive elements that can be drawn out from scientific investigations for giving whole-process innovative education on undergraduate students.
\end{abstract}

Keywords: Three-comprehensive education, Undergraduate students, Scientific investigations, Innovative capability, Electrospinning.

\section{INTRODUCTION}

"Three-comprehensive education" is a great plan put forward by the Central Committee of the Communist Party of China, which is aimed to strengthen and improve the ideological and political work in Chinese Colleges and Universities under the new situation. In this plan, it is pointed out clearly that colleges and universities should take moral cultivation as the fundamental task, integrate ideological and moral education, cultural knowledge education and social practice education, put ideological and political work through the whole process of education and teaching, and guide the ideological value through the whole process and every link of education and teaching. Thus, the education can be broadened and deepened from all the activities in the colleges and universities, including teaching, scientific research, practice, management, service, culture and organization.

Based on the spirit of three-comprehensive education, the role of scientific researchers can be further enhanced for fostering the professional talents for building the Socialism with Chinese characteristics. Shown in Figure 1, scientific investigations are able to infiltrate many positive elements in the threecomprehensive education. In terms of time, the whole process of education means that education should run through the whole process of students' learning and growth. Needless to say, scientific investigations can greatly promote the students' learning and growth, particularly their professional skills and the future career. In terms of space, all-round education emphasizes all aspects of the development of the students. It is no doubt that the scientific investigations are able to promote the general development in the aspects of moral, intellectual, and physical education. From the point of view of strength, all departments and employees in the school have the responsibility of educating people. During a scientific investigation, all the staff around the students should be able to provide their useful experiences to the students. For example, the lab administrator can tell them the safety knowledge. The professional teachers tell them the related 
mechanisms, and even the cleaner can show them the differences in keeping a clean laboratory.

Certainly, the classmates and the graduate student can also teach them, just as the Analects of Confucius: three people walk, there must be my teacher. And if the students are good at learning, there is a saying of Sakyamuni for them: "no matter who you meet, it is the person who should appear in your life. There are reasons and missions. It is no accident. This person will certainly teach you something". In a word, there are many useful elements in the scientific researches for carrying out the three-comprehensive education for the undergraduate students, which is often expressed as a scientific article.

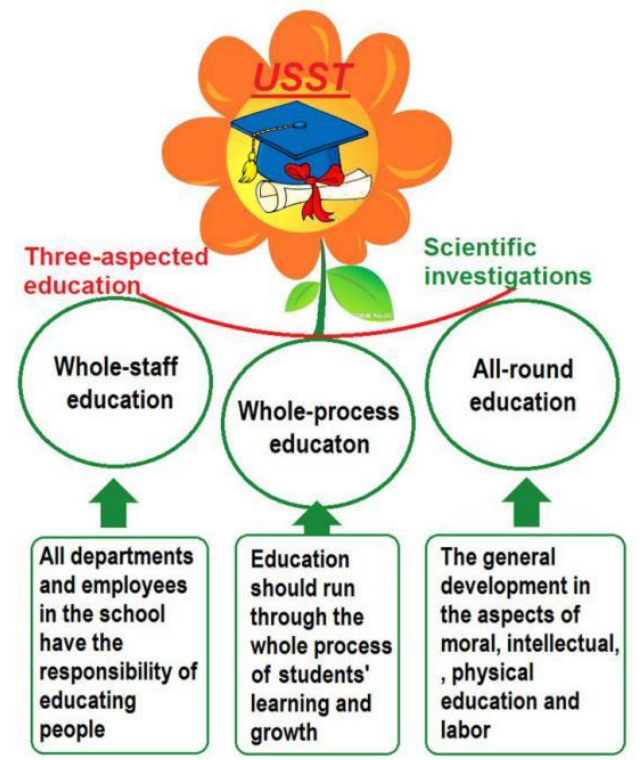

Figure 1 The role of scientific investigations in carrying out the popular "three-aspected education" in China university.

\section{INNOVATIVE CAPABILITY OF THE UNDERGRADUATE STUDENTS IS STILL THE MOST IMPORTANT CONTENTS FOR FOSTERING PROFESSIONAL TALENTS}

For a high quality talent, it is necessary that he or she has a series of excellent capabilities. Shown in Figure 2, on one hand, he or she must have good personal learning and working ability, which include learning ability, pressure resistance ability, executive ability, working enthusiasm, hard work, independent ability, enterprising spirit, moral cultivation, and so on. On the other hand, he or she should also have fine social life ability, which include professional skills, communication skills, adaptability, sense of responsibility, psychological adjustment, cooperation ability, organizational ability, and so on.

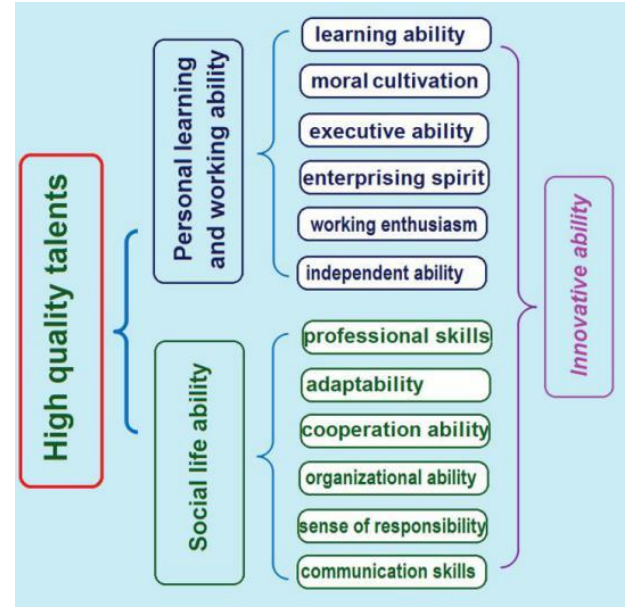

Figure 2 There are many abilities that are important for a high quality talent, and the innovative ability is able to interweave with all these important capabilities.

Among all those abilities, innovative ability is a very special one. It is able to interweave all the abovementioned abilities for further promoting the students' learning ability and social life ability. Scientific researches are activities that are full of innovations. It is no doubt that professional scientific investigations should be very useful for fostering the students' professional innovative thinking, which in turn will promote the students' abilities about many other aspects. Thus, the whole-process innovative education on undergraduate students should be advocated for their successes.

\section{THE DEVELOPING PROCESSES OF A SCIENTIFIC ARTICLE CAN BE A VERY USEFUL MATERIAL FOR A WHOLE- PROCESS EDUCATION}

A scientific article is a conclusion of the whole process of a scientific investigation. Often, the investigation is aimed to solve a key or difficult issue in a certain discipline. For example, chitosan is a natural polymer that can be extracted from many natural products. It can be exploited to deliver drug as a compatible drug carrier. Thus, both investigations and review articles are reported for developing chitosanbased nano drug delivery systems in literature [1,2]. Correspondingly, the related scientific publications can be very useful teaching materials for giving a wholeprocess education to the undergraduate students at a suitable time period.

Shown in Figure 3 is a typical explanation about a research process is equal to a whole-process education. Working fluids are frequently utilized in the electrohydrodynamic atomization processes (EHDA, including electrospraying [3, 4], 2-D printing of e-jetting model [5], and electrospinning [6,7]) for creating novel functional nanomaterials. Thus, the initiation of a related 
scientific research needs to reasonably select the raw materials, which should include the model drug, the solvent or solvent mixture, the additive, and the filamentforming polymers if the prepared nano products are medicated nanofibers [8, 9]. These contents should be vivid materials for the class teaching of theoretical contents to the undergraduate students for several professional courses such as "Materials science and Engineering", "Functional materials", "Polymer Science and Engineering", "Nano Science and Technology", and so on.

\section{$A$ research process $=A$ whole-process education}

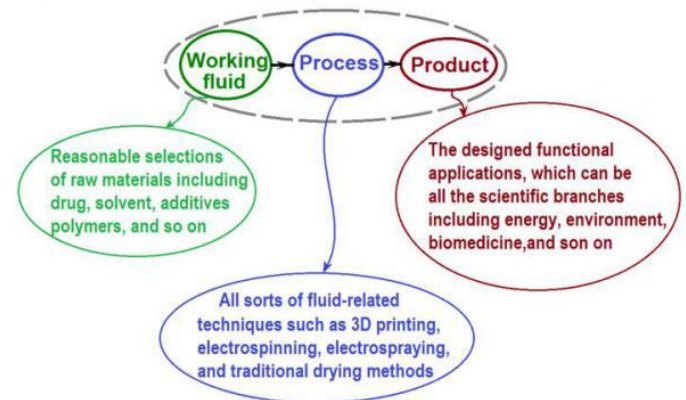

Figure 3 A developing process about synthesizing new kinds of functional nanomaterials, which is a very useful teaching material to conduct a whole-process education from selection of raw materials to all sorts of techniques, and finally to the desired products for functional applications

Later, the second step of the treatment of fluids into products involves the determination and selection of all sorts of fluid-related techniques, both the advanced EHDA processes and the traditional drying processes. These methods are just those important professional skills that the teachers should train the undergraduate students to become a professional talent in the future. The related preparation and also the materials analysis methods should be taught to the students in their professional courses such as "Modern material analysis methods", "Technologies for Materials science and Engineering", "Frontier of modern materials", and so on.

Finally, the characterization and potential applications of the products are able to greatly broaden the scientific views of the undergraduate students. This is because that the finish of the whole process is often an interdisciplinary thing and the potential applications of the products can be numerous $[10,11]$. Thus, how to design the functional applications of new materials is often not an easy thing, even for a high hand. A full and deep background about the discipline is needed for a right judgement. It is just because of this concern; the undergraduate students may need the intensive instructions from their teachers.

Certainly, besides the scientific investigations, how to organize the research results, how to write the scientific article, how to submit them to a suitable journal, and even how to respond the comments and suggestions of the editors and reviewers are all things that the undergraduate students can learn from the teachers. Vice visa, an active taking part in of the students will benefit them a lot about professional growths and developments.

\section{AN EXCELLENT EXAMPLE FOR PROFESSIONAL AND INNOVATIVE EDUCATION BASED ON A SCIENTIFIC INVESTIGATION ABOUT ELECTROSPINNING}

An active taking part in of the undergraduate students in the publication of a scientific article means a whole-process innovative education on them. This has two-layer meanings. One is that the undergraduate students are able to follow their teachers and even the graduate students to study and imitate the scientific investigations. Meanwhile, the practices can promote their comprehensions about the professional knowledge they have learned in their classrooms, and foster their capability of linking theories with practices. The other, and which is more important, is that the undergraduate students may put forward their own novel idea and finish the scientific investigations in a relatively independent manner, just as graduate students who are pursuing their Master or Ph.D degree.

The following case is just an excellent example for professional and innovative education and the related positive results based on a undergraduate student, whose name is Shuyue Chang. She received an education after following a graduate student for almost one year, and she gradually grasp the developments of electrospinning and the special multiple-fluid processes. Later, she put forward a brand-new complex nanostructure, which was realized due to a combination of her routine life experiences and the learned knowledge about nanostructures and EHDA processes

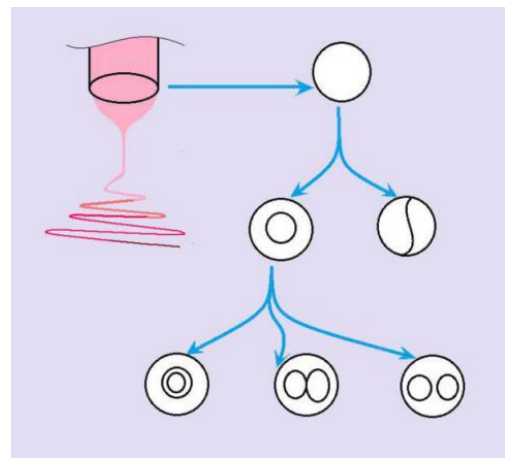

Figure 4 The developments of electrospinning methods themselves are an excellent whole-process teaching material for the students majoring in materials science and engineering. 
She has several pig accessories. One day, she suddenly thought of nano pig and nano pig noses when she saw the several structural spinnerets in the Lab of Electrohydridynamic Atomization \& Its Application in Creating Novel Materials, which is at the School of Materials Science and Engineering in the University of Shanghai for Science and Technology. Shown in Figure 4. is a whole developing process of spinneret utilized in electrospinning. To exploit a metal capillary as a spinneret to carry out a single-fluid blending electrospinning is the most common manner [12]. Later, electrospinning is divided out two new branches with the simultaneous treatment of two working fluids, i.e. coaxial and side-by-side [13-15]. Several years' before, spinneret with a three-layer concentric manner was developed to conduct a tri-axial electrospinning for creating tri-layer core-shell nanofibers [16-19]. Most recently, a tri-fluid electrospinning with a side-by-side core in a common sheath was reported [20]. Inspired by these structural characteristics, a variation with a separate side-by-side core in a common sheath occurred in Chang's brain, and then she put forward the "pig-nose" spinneret and the related "pig-nose" nanostructure $[21,22]$. Apparently, the developments of electrospinning itself is an excellent whole-process teaching material majoring in materials science and engineering and have brought out positive results from the students (Figure 5).

To fulfil a whole-process education from "raw material selection to working process, and to products for applications", Chang et al. were instructed to further conduct experiments to generate "pig-nose" nanostructures for drug delivery applications. The generated structural nanofibers were able to combine the performances of three different types of monolithic composites in the two separate cores and sheath sections, and promoted them to synergisticcally act to realize a common objective that the model drug was delivered based on the $\mathrm{pH}$ value of the digestive systems for a smart three-phase drug controlled release.

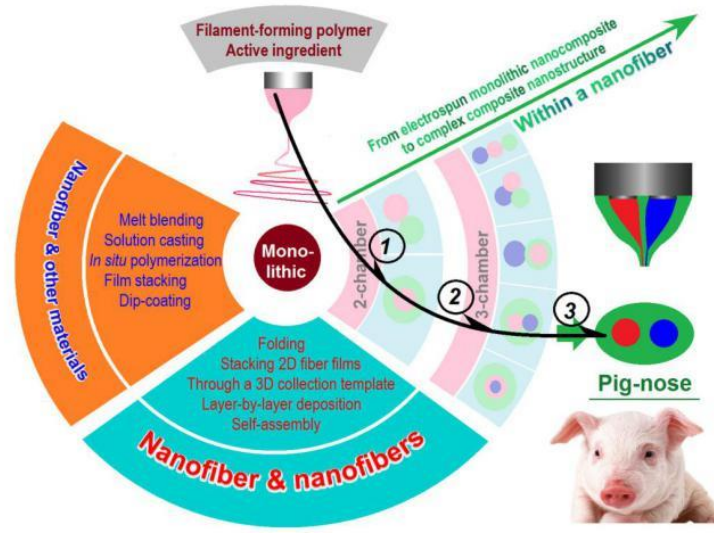

Figure 5 An interesting example about whole-process education about advanced technology for the undergraduate student, and the positive results from the student Shuyue Chang [21].

\section{CONCLUSION}

Three-comprehensive education is a great plan aimed to strengthen and improve the ideological and political work in Chinese Colleges and Universities under the new situation, which is very useful for training socialist successors in the new era. However, how to effectively carry out it poses a big challenge to all the staff in the colleges and universities. In this paper, scientific investigations are explored as a concrete example to find the important elements that can be utilized as teaching materials for threecomprehensive education. With electrospinning and electrospun "pig-nose" nanostructure produced in the Lab of Electrohydridynamic Atomization \& Its Application in Creating Novel Materials (the School of Materials Science and Engineering in the University of Shanghai for Science and Technology) by undergraduate student as examples, the progresses of a scientific investigation are recorded in detail, and the highlights for improving the students' innovative thinking and ability are discussed.

\section{AUTHORS' CONTRIBUTIONS}

Investigations: Y Liu, W He, S Guo \& W Zhou; draft preparation: Y Liu; rreview \& editing: DG Yu.

\section{ACKNOWLEDGMENTS}

This work was supported by the USST student innovation project (Nos. SH2020227 \& XJ20203762020378) and the Shanghai Natural Science Foundation (No.20ZR1439000). The helps from Shuyue Chang, Jie $\mathrm{Li}$ and Chen Dong are highly appreciated.

\section{REFERENCES}

[1] N.D. Al-Jbour, M.D. Beg, J. Gimbun, A.M.M. Alam, An overview of chitosan nanofibers and their applications in the drug delivery process, Curr. Drug Deliv. $16 \quad$ (2019) 272-294. DOI:10.2174/1567201816666190123121425

[2] X. Yang, S. Chen, X. Liu, M. Yu, X. Liu, Drug delivery based on nanotechnology for target bone disease, Curr. Drug Deliv. 16 (2019) 782-792. DOI:10.2174/1567201816666190917123948

[3] K. Wang, H.F. Wen, D.G. Yu, Y. Yang, D.F. Zhang, Electrosprayed hydrophilic nanocomposites coated with shellac for colon-specific delayed drug delivery, Mater. Des. $143 \quad$ (2018) 248-255. DOI:10.1016/j.matdes.2018.02.016

[4] W.D. Huang, X. Xu, H.L. Wang, J.X. Huang, X.H. Zuo, X.J. Lu, X.L. Liu, D.G. Yu, Electrosprayed ultra-thin coating of ethyl cellulose on drug nanoparticles for improved sustained release, 
Nanomaterials $\quad 10$

DOI:10.3390/nano10091758

[5] M. Wang, D.G. Yu, X. Li, G.R. Williams, The development and bio-applications of multifluid electrospinning, Mater. Highlight. 1 (2020) 001. DOI: 10.2991/mathi.k.200521.001

[6] M. Mofidfar, M.R. Prausnitz, Electrospun transdermal patch for contraceptive hormone delivery, Curr. Drug Deliv. 16 (2019) 577-583. DOI: $10.2174 / 1567201816666190308112010$

[7] M. Vlachou, S. Kikionis, A. Siamidi, K. Tragou, S. Kapoti, E. Ioannou, V. Roussis, A. Tsotinis, Fabrication and characterization of electrospun nanofibers for the modified release of the chronobiotic hormone melatonin, Curr. Drug Deliv. $16 \quad$ (2019) 79-85. DOI:10.2174/1567201815666180914095701

[8] R. Ramakrishnan, J. Gimbun, P. Ramakrishnan, B. Ranganathan, S.M.M. Reddy, G. Shanmugam, Effect of solution properties and operating parameters on needleless electrospinning of poly(ethylene oxide) nanofibers loaded with bovine serum albumin, Curr. Drug Deliv. 16 (2019) 913922. DOI:10.2174/1567201816666191029122445

[9] S. Padmakumar, D. Menon, Nanofibrous polydioxanone depots for prolonged intraperitoneal paclitaxel delivery, Curr. Drug Deliv. 16 (2019) 654-662.

DOI:10.2174/1567201816666190816102949

[10] P. Wang, M. Wang, X. Wan, H. Zhou, H. Zhang, D.G. Yu, Dual-stage release of ketoprofen from electrosprayed core-shell hybrid polyvinyl pyrrolidone/ethyl cellolose nanoparticles, Mater. Highlight. $\quad 1 \quad 002$. DOI:10.2991/mathi.k.200825.001

[11]Z.P. Liu, L.L. Zhang, Y.Y. Yang, D. Wu, G. Jiang, D.G. Yu, Preparing composite nanoparticles for immediate drug release by modifying electrohydrodynamic interfaces during electrospraying, Powder Technol. 327 (2018) 179187. DOI: 10.1016/j.powtec.2017.12.066

[12] Y. Bai, D. Wang, Z. Zhang, J. Pan, Z. Cui, D.G. Yu, S.W.A. Bligh, Testing of fast dissolution of ibuprofen from its electrospun hydrophilic polymer nanocomposites, Polym. Test. 91 (2020) 106872. DOI:10.1016/j.polymertesting.2020.106872

[13] M. Wang, D. Li, J. Li, S. Li, Z. Chen, D.G. Yu, Z. Liu, J.Z. Guo, Electrospun Janus zein-PVP
[14] nanofibers provide a two-stage controlled release of poorly water-soluble drugs, Mater. Design 196 (2020) 109075. DOI:10.1016/j.matdes.2020.109075

[15] S. Kang, S. Hou, X. Chen, D.G. Yu, L. Wang, X. Li, G.R. Williams, Energy-saving electrospinning with a concentric Teflon-core rod spinneret to create medicated nanofibers, Polymers 12 (2020) 2421. Doi:10.3390/polym12102421

[16] Y. Ding, C. Dou, S. Chang, Z. Xie, D.G. Yu, Y. Liu, J. Shao, Core-shell Eudragit S100 nanofibers prepared via triaxial electrospinning to provide a colon-targeted extended drug release, Polymers 12 (2020) 2034. DOI:10.3390/polym12092034

[17] K. Wang, P. Wang, M. Wang, D.G. Yu, F.X. Wan, S.W. Annie Bligh, Comparitive study of electrospun crystal-based and composite-based drug nano depots, Mater. Sci. Eng. C 113 (2020) 110988. DOI:10.1016/j.msec.2020.110988

[18] M. Wang, J. Hou, D.G. Yu, S. Li, J. Zhu, Z. Chen, Electrospun tri-layer nanodepots for sustained release of acyclovir, J. Alloy. Compd. 846 (2020) 156471. DOI:10.1016/j.jallcom.2020.156471

[19] Y. Yang, S. Chang, Y. Bai, Y. Du, D.G. Yu, Electrospun triaxial nanofibers with middle blank cellulose acetate layers for accurate dual-stage drug release, Carbohydr. Polym. 243 (2020) 116477. DOI: 10.1016/j.carbpol.2020.116477

[20]C.K. Huang, K. Zhang, Q. Gong, D.G. Yu, J. Wang, X. Tan, H. Quan, Ethylcellulose-based drug nano depots fabricated using a modified triaxial electrospinning, Int. J. Biol. Macromol. 152 (2020) 68-76. DOI: 10.1016/j.ijbiomac.2020.02.239

[21]D.G. Yu, M. Wang, X. Li, X. Liu, L.-M. Zhu, S.W. Annie Bligh, Multifluid electrospinning for the generation of complex nanostructures, Wiley Interdiscip. Rev. Nanomed. Nanobiotechnol. 12 (2020) 1601. DOI: 10.1002/wnan.1601

[22] Y. Liu, X. Liu, P. Liu, X. Chen, D.G. Yu, Electrospun multiple-chamber nanostructure and its potential self-healing applications, Polymers 12 (2020) 2413. DOI:10.3390/polym12102413

[23] S. Chang, M. Wang, F. Zhang, Y. Liu, X. Liu, D.G. Yu, H. Shen H, Sheath-separate-core nanocomposites fabricated using a trifluid electrospinning. Mater. Des. 192 (2020) 108782. DOI: $10.1016 /$ j.matdes.2020.108782 